\title{
Application of the collective model to determine some rotational bands of ${ }^{239} \mathrm{U}$ nucleus
}

\author{
Nguyen An Son ${ }^{1}$, Le Viet Huy ${ }^{1}$, Pham Ngoc Son ${ }^{2}$
}

\begin{abstract}
U}$ material is component in fuels of nuclear reactor core. Understanding properties and structure of ${ }^{238} \mathrm{U}$ nucleus is necessary before simulating and designing nuclear reactor. Besides that, the study of nuclear reaction is necessary to identify the specific characteristics of nucleus, it is the most effective experimental method up to now. However, in order to explain the properties of nuclear structure, in addition to study of the nuclear reaction, nuclear structure models and its theory must be used. There are many nuclear structure models to solve those properties of nucleus. This paper presents application of the Collective Model to determine some rotational bands of ${ }^{239} \mathrm{U}$ nucleus, using Prompt gamma neutron activation analysis method (PGNAA). Experiment is performed at channel No.2 of Dalat Research Reactor (DRR), using Filtered Thermal Neutron Beam and Compton Suppression Spectroscopy with High - Purity Germanium detector (HPGe). The results have found 11 rotational bands of ${ }^{239} \mathrm{U}$ nucleus. This work is very necessary for the research of nuclear structure which controls material technology by itself.
\end{abstract} bands

Index Terms - Collective model, ${ }^{239} \mathrm{U}$, rotational

\section{INTRODUCTION}

$\mathrm{C}$ ollective Model was developed in the 1950s by Reynolds, A. Bohr and Mottelson, Hill and Wheele [1]. The Collective Model emphasizes the coherent behavior of all nucleons in heavy nuclei. The spherical symmetric potential of the nucleus with full shell is exceptionally stable to the effects of additional nucleons. Therefore, it still remains spherical symmetric form. The excited state of a nucleus is defined by single-particle levels in the spherical symmetric potential and the quadrupole field of a spherical symmetric nucleus.

Received: 17-07-2017, Accepted: 14-08-2017, Published: 10-8-2018

Author: Nguyen An Son, Le Viet Huy- Da Lat University (e-mail: sonna@dlu.edu.vn) Pham Ngoc Son - Nuclear Research Institute
By the increase of external nucleons of the full shell of nucleus, the individual motion effect of nucleons on the potential field increases and the centrifugal pressure of nucleons appears.

Collective motion increases rapidly and impact the core of full shell nucleus leading to the decrease of the potential field stability, it means that the nucleus has spherical asymmetric form. According to quantum mechanics, spherical asymmetric nuclei can rotate.

The Collective Model has been very successful in describing variety of nuclear properties, especially energy levels in nuclei that the Shell Model and the Liquid Drop Model cannot be applied. These energy levels show the characteristics of rotating or vibrating systems. The properties of these nuclei, including excited state energies, angular momentum, magnetic moments, nuclear shapes, etc. can be understood by using the Collective Model.

In 1969, Larry Shelton Varnell [2] applied the Collective Model to determine the rotational band of some deformed nuclei, using the vacuum chamber of the $\mathrm{Si}(\mathrm{Li})$ electron spectrometer with Lithium Drifted Silicon detector. The result had determined 12 rotational bands of ${ }^{152} \mathrm{Sm}, 14$ rotational bands of ${ }^{154} \mathrm{Gd}$, and 12 rotational bands of ${ }^{166} \mathrm{Er}$.

So far, there are many researches on ${ }^{239} \mathrm{U}$ nucleus. In 1959, the smoothed gamma-ray spectrum due to neutron capture by ${ }^{238} \mathrm{U}$ obtained by Campion et al [3]. The gamma rays in the energy region between $0.14 \mathrm{MeV}$ and $3.4 \mathrm{MeV}$ were examined with a crystal spectrometer. The gamma-rays in the $3.4 \mathrm{MeV}$ to $4.2 \mathrm{MeV}$ range were studied using a pair spectrometer with a resolution of about $1 \%$. In the 1972 s, Booth et al [4] had found 21 discrete energy levels and the spin-parity assignments of the excited ${ }^{239} \mathrm{U}$ nucleus up to $0.950 \mathrm{MeV}$. In the $1970 \mathrm{~s}$, John et al [5] studied about neutron capture gamma radiation from neutron capture in ${ }^{238} \mathrm{U}$. The results had found 16 energy gamma-rays from $1 \mathrm{MeV}$ to 4.75 $\mathrm{MeV}$, with the intensity was reported on a number per one hundred capture events, etc. But there have 
no research before about the rotational band of ${ }^{239} \mathrm{U}$ nucleus.

Prompt gamma neutron activation analysis (PGNAA) is a rapid, nondestructive sample technique which is very effective in nuclear structure research [6]. ${ }^{238} \mathrm{U}$ exists in nature, its abundance is about $99.27 \%$, which is component in fuels of nuclear reactor core. ${ }^{238} \mathrm{U}$ is heavy eveneven nucleus which has 92 protons and 146 neutrons. ${ }^{239} \mathrm{U}$ is heavy even-odd nucleus which has 92 protons, 146 neutrons and 1 added neutron. In this experiment, PGNAA method is used to acquire the prompt gamma-rays emitted from ${ }^{238} \mathrm{U}$ $(\mathrm{n}, \gamma){ }^{239} \mathrm{U}$ reaction.

$$
{ }_{0}^{1} n+{ }_{92}^{238} U \rightarrow\left({ }_{92}^{239} U\right){ }^{*} \rightarrow{ }_{92}^{239} U+\gamma_{\text {prompt }}
$$

Where $n$ is incident neutron, ${ }^{238} U$ is the target nucleus, $\left({ }^{239} U\right)^{*}$ is compound nucleus, $\left({ }^{239} U\right)$ is product nucleus and $\gamma_{\text {prompt }}$ is prompt gamma-rays.

\section{THEORY AND EQUIPMENTS}

\section{Theory}

The Nilsson model is a shell model for a deformed nucleus. It provides a description of single-particle motion in a spherical asymmetric potential. An appropriate single-particle Hamiltonian for a nucleus with the symmetry axis $\mathrm{z}$ is given by [7]:

$$
H=T+V=\frac{p^{2}}{2 m}+\frac{1}{2} m\left[\omega_{x}\left(x^{2}+y^{2}\right)+\omega_{z} z^{2}\right]+C l s+D l^{2}
$$

where $\omega_{x}, \omega_{y}$ and $\omega_{z}$ are one-dimensional oscillator frequencies in the $x, y$, and $z$ direction. $C$ and $D$ are constant. The $l^{2}$ and $l s$ terms ensure the proper order and energies of the single-particle levels in the spherical limit.

$$
\begin{gathered}
\omega_{x}^{2}=\omega_{y}^{2}=\omega_{0}^{2}\left(1+\frac{2}{3} \delta\right) ; \\
\omega_{z}^{2}=\omega_{0}^{2}\left(1-\frac{4}{3} \delta\right) ; \\
\omega_{0}=\left(1-\frac{4}{3} \delta^{2}-\frac{16}{27} \delta^{3}\right)^{-\frac{1}{6}}=\text { constant }
\end{gathered}
$$

where $\omega_{0}$ is the oscillator frequency in the spherical potential. It is assumed that the nuclear volume remains constant as a function of $\omega_{0}$. The rotational Hamiltonian is of the form [7]:
$H_{\text {rot }}=\frac{\Omega^{2}}{2 J_{\text {eff }}}=\frac{I^{2}-K^{2}}{2 J_{\text {eff }}}=\frac{\hbar^{2}}{2 J_{\text {eff }}}[I(I+1)-K(K+1)]$

where $I$ is a total angular momentum, $\Omega$ is rotational angular momentum and $K$ is the spin of nucleus.

$$
\begin{gathered}
\vec{I}=\vec{K}+\vec{\Omega} ; \\
I^{2}=\hbar^{2} I(I+1) ; K^{2}=\hbar^{2} K(K+1)
\end{gathered}
$$

$J_{\text {eff }}$ is the effective moment of inertia,

$$
J_{\text {eff }} \approx J_{0}\left(\frac{\Delta R}{R}\right)^{2}
$$

where $J_{0}$ is the moment of the inertia of nucleus, $R$ is radius of nucleus and $\Delta R$ is a deformation parameter of nucleus.

In deformed even-even nuclei, the spin of nucleus is in the ground state $(K=0)$, equation (2) can be written [1]:

$$
E_{\text {rot }}=\frac{\hbar^{2}}{2 J_{\text {eff }}} I(I+1)
$$

where $I=0,2,4,6, \ldots$ for positive parity states $(\pi$ $=+1)$ and $I=1,3,5,7, \ldots$ for negative parity states $(\pi=-1)$.

In deformed odd-A and odd-odd nuclei $(K \neq 0)$, equation (2) can be written [1]:

$$
E_{r o t}=\frac{\hbar^{2}}{2 J_{\text {eff }}}[I(I+1)-K(K+1)]
$$

where $I=K, K+1, K+2, K+3, \ldots$

${ }^{239} \mathrm{U}$ nucleus has spin $K=5 / 2$ and $I=K, K+1$, $K+2, \ldots=5 / 2,7 / 2,9 / 2, \ldots$ Thus, rotational energies are:

$$
E_{0}=0 ; E_{1}=\frac{7 \hbar^{2}}{2 J_{e f f}} ; E_{2}=\frac{16 \hbar^{2}}{2 J_{e f f}} ; E_{3}=\frac{27 \hbar^{2}}{2 J_{e f f}} ;
$$$$
E_{4}=\frac{40 \hbar^{2}}{2 J_{e f f}} ; E_{5}=\frac{55 \hbar^{2}}{2 J_{e f f}} ; E_{6}=\frac{72 \hbar^{2}}{2 J_{e f f}} ; \ldots
$$

Then, the ratio between rotational energies is given by:

$$
E_{1} / E_{2} / E_{3} / E_{4} / E_{5} / E_{6} / \ldots=1 / \frac{16}{7} / \frac{27}{7} / \frac{40}{7} / \frac{55}{7} / \frac{72}{7} / \ldots
$$

\section{Equipments}

The experiment is performed at channel No.2 of DRR, which using Filtered Thermal Neutron Beam, and HPGe detector with PGNAA method. Configuration of the system is shown in Fig. 1. 


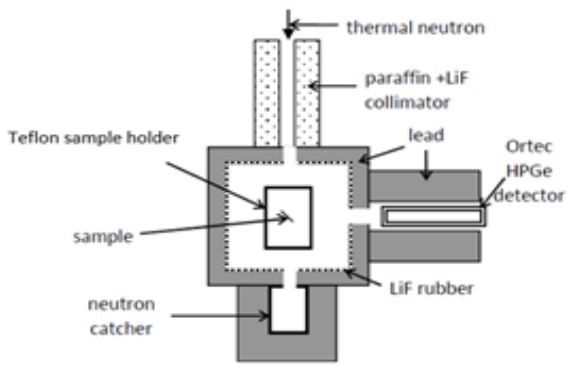

Fig. 1. Configuration of the acquisition system at channel No. 2 of DRR

The thermal neutron flux at the sample position is $1.6 \times 10^{6} \mathrm{n} / \mathrm{cm}^{2} \mathrm{xs}$, and the Cd ratio is 420 [8]. Inside the channel No.2, a chamber with the internal high density polyethylene (HDPE) is set up, it also has $5 \% \mathrm{Li}$ to shield the scattered neutrons. In the mid-core of this chamber, a holder is made of PTFE (Teflon plastic) material which fixed the sample during the acquisition process.

Due to the large number of gamma-rays incident on the main detector, the Compton continuum is a significant hindrance for low background. The Compton continuum causes the difficult search of low-intensity peaks and increases the uncertainty of the measured activities. Therefore, a Compton suppression spectroscopy has been set-up and installed at DRR $500 \mathrm{~kW}$ for neutron activation analysis and nuclear data measurement. The central detector is a GR7023 Canberra n-type coaxial HPGe detector. Its FWHM is $2.36 \mathrm{keV}$ for the $1.33 \mathrm{MeV}$ of ${ }^{60} \mathrm{Co}$ peak. The relative efficiency is $72 \%$. There are 12 Bismuth Germanium (BGO) guard detectors shielded by a lead of $10 \mathrm{~cm}$ thickness. A lead-stepped collimator is located in the front of the opening of the guard detectors. The length and inner diameter of the lead collimator are $180 \mathrm{~mm}$ and $40 \mathrm{~mm}$, respectively. The reduction of the Compton continuum has been achieved by surrounding the HPGe detector with the BGO detectors whose signals are used for the anti-coincidence gating in the analog-to-digital converter (ADC). The Compton continuum is reduced about 1.5 to 2 times, up to $1 \mathrm{MeV}$ region of energy [9]. The detectors and shielding system are configured as Fig. 2.

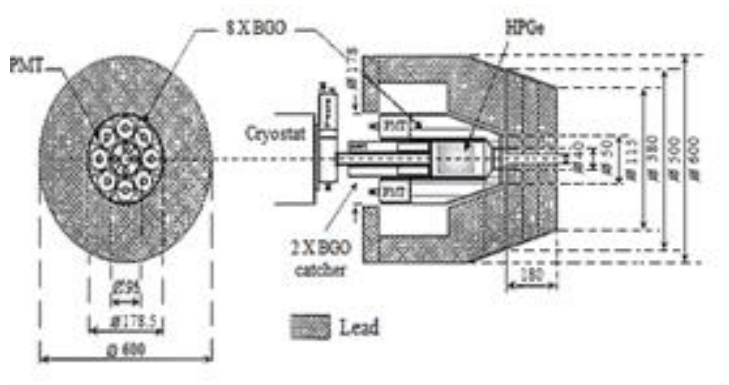

Fig. 2. The back and the cross-sectional view of the detectors and shielding system

The electronic modules are manufactured by Canberra except the high voltage module for BGO detectors, which were produced by Fast Comptec. They include 2026 main amplifiers (AMP), 3106D high voltage power supply, multiport II with ADC $16 \mathrm{~K}$ and multichannel analyzer (MCA), using the Genie 2000 software. Its configuration is shown in Fig. 3.

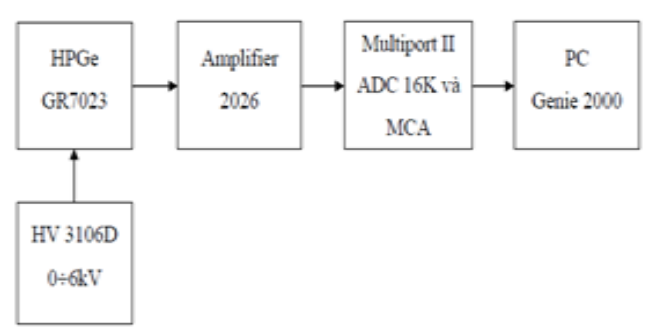

Fig. 3. The block schema of the gamma acquisition system

${ }^{238} \mathrm{U}$ natural metal is used. Its diameter, thickness and weight are $1.2 \mathrm{~cm}, 0.5 \mathrm{~cm}$ and $23.68586 \mathrm{~g}$ respectively. Geometric form of ${ }^{238} \mathrm{U}$ sample is cylinder form, which is shown in Fig. 4.

The ${ }^{238} \mathrm{U}$ sample is placed in the holder at the irradiation position, the angle between the neutron flux and the sample is $45^{\circ}$, the distance from the sample to the detector is $38.5 \mathrm{~cm}$.

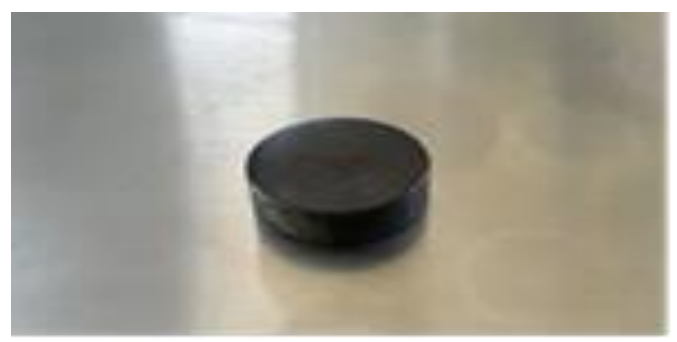

Fig. 4. Geometric form of $238 \mathrm{U}$ 


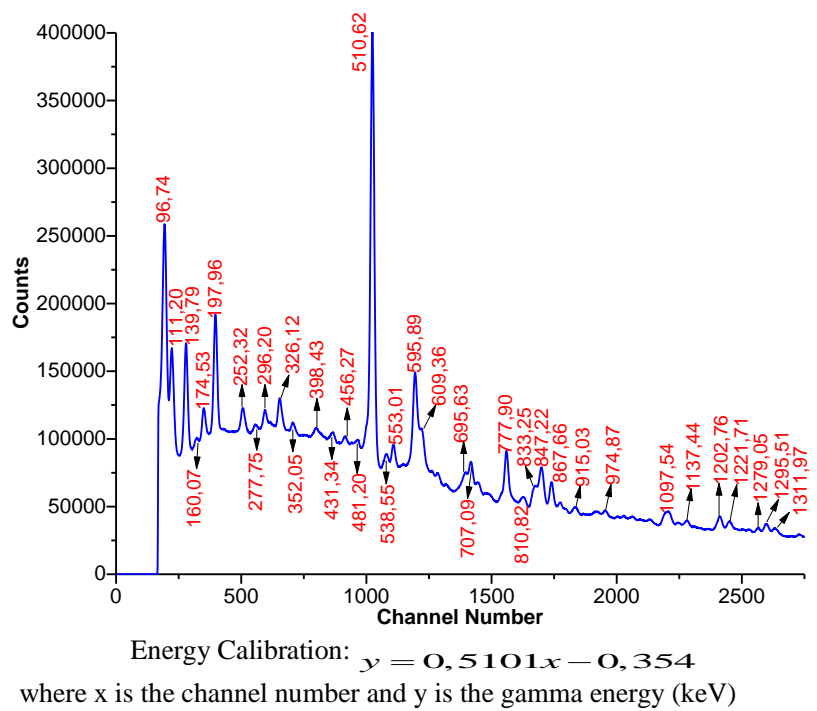

Fig. 5. Prompt gamma spectrum of ${ }^{239} \mathrm{U}$

\section{RESULTS AND DISCUSSION}

The acquisition time of background spectrum is 62,465 seconds and ${ }^{239} \mathrm{U}$ spectrum is 86,492 seconds.

Prompt gamma spectrum of ${ }^{239} \mathrm{U}$ acquired at channel No.2 of DRR after eliminating the effect of background is shown in Fig. 5. The statistical count of the spectrum is $1.92 \times 108$ counts.

Experimental data are shown in Table 1. There are 36 prompt gamma-rays emitted from ${ }^{238} \mathrm{U}(\mathrm{n}, \gamma)$ ${ }^{239} \mathrm{U}$ reaction. Determination of rotational bands of ${ }^{239} \mathrm{U}$ is calculated by Equation (5) and (6). Results compared between experimental data and theoretical calculation are shown in Table 2.

Table 1. Energy and Intensity of prompt gamma-rays emitted from ${ }^{238} \mathrm{U}(\mathrm{n}, \gamma){ }^{239} \mathrm{U}$ reaction

\begin{tabular}{|c|c|c|}
\hline No. & Energy (keV) & $\begin{array}{c}\text { Intensity } \\
(\%)\end{array}$ \\
\hline 1 & 96.74 & 0.7403 \\
\hline 2 & 111.20 & 0.4581 \\
\hline 3 & 139.79 & 0.0057 \\
\hline 4 & 160.07 & 0.2853 \\
\hline 5 & 174.53 & 0.2840 \\
\hline 6 & 197.96 & 0.0382 \\
\hline 7 & 252.32 & 0.6360 \\
\hline 8 & 277.75 & 0.9082 \\
\hline 9 & 296.20 & 1.0473 \\
\hline 10 & 326.12 & 0.9353 \\
\hline 11 & 352.05 & 1.4591 \\
\hline 12 & 398.43 & 1.7781 \\
\hline
\end{tabular}

\begin{tabular}{|c|c|c|}
\hline No. & Energy (keV) & Intensity (\%) \\
\hline 13 & 431.34 & 1.9458 \\
\hline 14 & 456.27 & 2.0985 \\
\hline 15 & 481.20 & 2.2686 \\
\hline 16 & 510.62 & 9.2938 \\
\hline 17 & 538.55 & 2.9969 \\
\hline 18 & 553.01 & 3.5011 \\
\hline 19 & 595.89 & 1.6280 \\
\hline 20 & 609.36 & 3.8907 \\
\hline 21 & 695.63 & 3.7557 \\
\hline 22 & 707.09 & 3.3245 \\
\hline 23 & 777.90 & 6.4912 \\
\hline 24 & 810.82 & 3.3157 \\
\hline
\end{tabular}

\begin{tabular}{|c|c|c|}
\hline No. & Energy (keV) & Intensity (\%) \\
\hline 25 & 833.25 & 4.0339 \\
\hline 26 & 847.22 & 5.6266 \\
\hline 27 & 867.66 & 1.8530 \\
\hline 28 & 915.03 & 3.7763 \\
\hline 29 & 974.87 & 3.9210 \\
\hline 30 & 1097.54 & 3.4827 \\
\hline 31 & 1137.44 & 3.4598 \\
\hline 32 & 1202.76 & 3.3756 \\
\hline 33 & 1221.71 & 5.1242 \\
\hline 34 & 1279.05 & 4.6383 \\
\hline 35 & 1295.51 & 2.9494 \\
\hline 36 & 1311.97 & 4.6733 \\
\hline
\end{tabular}


Table 2. Results compared between experimental data and theoretical calculation

\begin{tabular}{|c|c|c|c|}
\hline No. & $\begin{array}{c}\mathbf{E}_{\gamma} \text { experimental } \\
(\mathbf{k e V})\end{array}$ & $\begin{array}{c}\left(\mathbf{E}_{\mathbf{i}} / \mathbf{E}_{\mathbf{1}}\right) \\
\text { experimental } \\
(\mathbf{k e V})\end{array}$ & $\begin{array}{c}\left(\mathbf{E}_{\mathbf{i}} / \mathbf{E}_{\mathbf{1}}\right) \\
\text { theory } \\
(\mathbf{k e V})\end{array}$ \\
\hline 1 & $(42.53)$ & 1.00 & 1.00 \\
\hline 2 & 96.74 & 2.27 & 2.29 \\
\hline 3 & 160.07 & 3.76 & 3.86 \\
\hline 4 & 252.32 & 5.93 & 5.71 \\
\hline 5 & 326.12 & 7.67 & 7.86 \\
\hline 6 & 431.34 & 10.14 & 10.26 \\
\hline
\end{tabular}

\begin{tabular}{|c|c|c|c|}
\hline No. & $\begin{array}{c}\mathbf{E}_{\gamma} \text { experimental } \\
(\mathbf{k e V})\end{array}$ & $\begin{array}{c}\left(\mathbf{E}_{\mathbf{i}} / \mathbf{E}_{\mathbf{1}}\right) \\
\text { experimental } \\
(\mathbf{k e V})\end{array}$ & $\begin{array}{c}\left(\mathbf{E}_{\mathbf{i}} / \mathbf{E}_{\mathbf{1}}\right) \\
\text { theory } \\
(\mathbf{k e V})\end{array}$ \\
\hline 7 & 553.01 & 13.00 & 13.00 \\
\hline 8 & 695.63 & 16.36 & 16.00 \\
\hline 9 & 810.82 & 19.06 & 19.26 \\
\hline 10 & 974.87 & 22.92 & 22.86 \\
\hline 11 & 1137.44 & 26.74 & 26.71 \\
\hline 12 & 1311.97 & 30.85 & 30.86 \\
\hline
\end{tabular}

*Note: $(42,53) \mathrm{keV}$ is taken from Nuclear Data Center [10]

Results in Table 2 show that ${ }^{239} \mathrm{U}$ nucleus has 11 rotational bands, which are $96.74 \mathrm{keV} ; 160.07$ $\mathrm{keV} ; 252.32 \mathrm{keV} ; 326.12 \mathrm{keV}$; $431.34 \mathrm{keV} ; 533.01$ $\mathrm{keV} ; 695.63 \mathrm{keV} ; 810.82 \mathrm{keV} ; 974.87 \mathrm{keV}$; $1137.44 \mathrm{keV}$ and $1311.97 \mathrm{keV}$. Among 36 energy peaks from the prompt gamma spectrum of ${ }^{239} \mathrm{U}$ nucleus, 25 another peaks are from ${ }^{235} U(n, \gamma){ }^{236} U$ reaction (abundance of ${ }^{235} \mathrm{U}$ nucleus in the sample is about $0.73 \%$ ) and from the background spectrum. However, we can't find the $42.53 \mathrm{keV}$ peak from the spectrum which is the first excited state of ${ }^{239} U$ nucleus [10]. It's the limitation of experimental procedure.

Howerer the determination of 11 peak energies of the experimental spectrum is very closed to the theoretical calculation of rotational bands by using Equation (6). Therefore we can conclude that the $42.53 \mathrm{keV}$ energy is a part of rotational bands.

\section{CONCLUSION}

From prompt gamma spectra acquired at the channel No.2 of DRR using application of Collective Model in nuclear structure research, some rotational bands of ${ }^{239} \mathrm{U}$ deformed nucleus are identified.

The results are quite relevant to the theory of the Collective Model when studying about the heavy nucleus, which has large different between the neutron and proton numbers. These results have shown that the ${ }^{239} \mathrm{U}$ deformed nucleus has spherical asymmetric structure.

\section{REFERENCES}

[1]. A. Bohr, B.R. Mottelson, Nuclear Structure, World Scientific Publishing, pp. 24, 33, 335, 1998.

[2]. L.S. Varnell, Beta, Gamma Vibrational bands in Deformed Nuclei, California Institute of Technology, May 19, 1969.

[3]. P.J. Campion, J.W. Knowles, G. Manning, G. A. Bartholomew, Canadian Journal of Physics , 1959.

[4]. R.S. Booth, J.E. White, S.K. Penny, K.J. Yost, Nuclear Science and Engineering, 1972.

[5]. J. Joh, V.J. Orphan, Gamma Rays From Resonant Capture of Neutrons in ${ }^{238} \mathrm{U}$, GA-10186, Gulf General Atomic (1970).

[6]. Z.B. Alfassi, Prompt Gamma Neutron Activation Analysis with Reactor Neutrons, pp. 59, 1995.

[7]. R.F. Casten, Nuclear Structure from a Simple Perspective, Oxford University Press, pp 167, 256, 257, 1990.

[8]. P.N. Sơn, "Phát triển dòng notron phin lọc trên kênh ngang số 2 của Lò phản ứng hạt nhân Đà Lạt”, Báo cáo Tổng kết đề tài nghiên cúu khoa học cấp Bộ, 2011.

[9]. N.X. Hai, N.N. Dien, P.D. Khang, V.H. Tan, N.D. Hoa, "A simple configuration setup for Compton Suppression Spectroscopy”, Cornell University Library 2013.

[10]. National Nuclear Data Center: https://www.nndc.bnl.gov/chart/reColor.jsp?newColor=f es 


\title{
Úng dụng mẫu hạt nhân suy rộng trong việc xác định một số phổ quay của hạt nhân ${ }^{239} \mathrm{U}$
}

\author{
Nguyễn An Sơn ${ }^{1}$, Lê Viết Huy ${ }^{1}$, Phạm Ngọc Sơn ${ }^{2}$ \\ ${ }^{1}$ Trường Đại học Đà Lạt \\ ${ }^{2}$ Viện Nghiên chứu Hạt nhân, Lâm Đồng, Việt nam \\ Tác giả liên hệ: sonna@dlu.edu.vn \\ Ngày nhận bản thảo: 17-07-2017, ngày chấp nhận đăng: 14-08-2017, ngày đăng: 10-08-2018
}

Tóm tắt - Vật liệu ${ }^{238} \mathrm{U}$ là thành phần trong nhiên liệu của lõi lò phản ứng hạt nhân. Việc tìm hiểu tính chất, cấu trúc của hạt nhân ${ }^{238} \mathrm{U}$ là cần thiết trước khi muốn mô phỏng, thiết kế lò phản ứng. Bên cạnh đó, nghiên cứu phản ứng hạt nhân là cần thiết trong việc xác định tính chất đặc thù của từng hạt nhân và là phương pháp thực nghiệm hữu hiệu cho đến ngày nay. Tuy nhiên, để giải thích các tính chất về cấu trúc hạt nhân, ngoài việc nghiên cứu phản ứng thì phải sử dụng các mẫu cấu trúc hạt nhân để làm sáng tỏ vấn đề. Có nhiều mẫu cấu trúc hạt nhân khác nhau để giải quyết cho bài toán này.

Tù khóa - Mẫu suy rộng, ${ }^{239} \mathrm{U}$, phổ quay
Bài báo trình bày ứng dụng mẫu suy rộng trong việc xác định một số phổ quay của hạt nhân ${ }^{239} \mathrm{U}$, sử dụng phương pháp phân tích kích hoạt neutron đo gamma tức thời (PGNAA). Thực nghiệm được tiến hành tại kênh ngang số 2 của Lò phản ứng hạt nhân Đà Lạt (DRR), sử dụng dòng neutron phin lọc đơn năng và hệ phổ kế triệt Compton với đầu dò bán dẫn HPGe. Kết quả đã xác định được 11 phổ quay của hạt nhân ${ }^{239} \mathrm{U}$. Đây là công việc thiết thực trong nghiên cứu cấu trúc hạt nhân và làm chủ công nghệ vật liệu. 